\title{
Análise de uma proposta de atividade para o ensino médio sob a ótica dos aspectos emocionais no processo de ensino e aprendizagem
}

\author{
Analysis of a proposed activity for high school from the emotional aspects perspectivea in the \\ teaching-learning process \\ M. E. Sena ${ }^{1 *}$; D. F. Adamatti ${ }^{1}$; C. M. Machado ${ }^{1}$ \\ ${ }^{I}$ Programa de Pós-Graduação em Modelagem Computacional - PPGMC, Universidade Federal do Rio Grande - \\ FURG, Km 8, Av. Itália - Carreiros, Rio Grande - RS-Brasil \\ *elenicesena52@yahoo.com.br \\ (Recebido em 20 de abril de 2017; aceito em 22 de maio de 2017)
}

\begin{abstract}
Neste trabalho, apresenta-se uma proposta de atividade para a inserção da Teoria dos Grafos no Ensino Médio através de uma ferramenta computacional de aprendizagem. No Ensino de Matemática, a utilização de recursos, sobretudo digitais, como os softwares e os objetos de aprendizagem, representa a possibilidade de aprender Matemática de forma reflexiva, construtiva e autônoma. Oportunizar ao estudante do Ensino Médio a possibilidade de desenvolver habilidades importantes, tais como explorar, analisar, e modelar problemas do cotidiano, através da Teoria dos Grafos, pode proporcionar ao estudante a aptidão necessária para participar efetivamente deste mundo moderno onde é cada vez mais valorizado o conhecimento tecnológico. Diante disso os jovens estariam mais preparados e seguros para lidar com as situações do mundo, estariam tendo sua autoestima aprimorada na escola, além de desenvolver os aspectos cognitivos estariam desenvolvendo seus aspectos emocionais em relação a si mesmos o que os torna cada vez mais capazes de reagir e lidar com situações reais apresentadas diariamente. Formar cidadãos com consciência de si e de seu papel no mundo, promover mudanças, auxiliar na tomada de decisão, refletir e questionar contribui de forma positiva para um ensino de melhor qualidade.
\end{abstract}

Palavras-chave: Ensino Médio, Matemática, Teoria dos Grafos

In this paper, a proposal of activity for the insertion of the Graphs Theory in High School through a computational learning tool is presented. In mathematics teaching, the use of resources, especially digital ones, such as softwares and learning objects, represents the possibility of learning mathematics in a reflexive, constructive and autonomous way. The possibility of developing high-level skills such as exploring, analyzing and modeling daily problems through the graphs theory can give the student the ability to participate effectively in this modern world where more valued technological knowledge. In this way, teenagers would be better prepared and confident to deal with situations in the world, they would have their self-esteem improved in school, and developing the cognitive aspects would be developing their emotional aspects towards themselves, which would make them more capable to react and deal with real situations presented daily. Educating citizens with self-awareness and their role in the world, promoting change, assisting in decision-making, reflecting and questioning, could contribute positively to better quality teaching.

Keywords: High School, Mathematics, Graph Theory

\section{INTRODUÇÃO}

O quadro atual de educação nos mostra grande desmotivação e desinteresse dos estudantes em relação ao estudo hoje em dia, principalmente no ensino básico (fundamental e médio). Na busca pela melhora na qualidade do ensino, a partir da perspectiva de envolvimento do estudante no processo de ensino e aprendizagem, muitos professores tem buscado novas maneiras de ensinar os conteúdos, mudanças de métodos e ainda novos conteúdos para compor o currículo que possuam aplicação no cotidiano e mostrem para o estudante a importância daquilo que ele estuda na sala de aula. Brasil [3] destaca que:

o Ensino Médio tem como finalidades centrais não apenas a consolidação e o aprofundamento dos conhecimentos adquiridos durante o nível fundamental, no intuito de garantir a continuidade de estudos, mas também a preparação para 
o trabalho e para o exercício da cidadania, a formação ética, o desenvolvimento da autonomia intelectual e a compreensão dos processos produtivos.

No entanto para que isso ocorra é necessário repensar sobre o ensino de Matemática promovendo a participação ativa dos estudantes, buscando conteúdos de aplicação prática que desenvolvam habilidades de raciocínio, análise, pensamento crítico, tomada de decisão, entre outros. Ainda é necessário levarmos em consideração que grande parte dos estudantes possui um relacionamento complicado com a Matemática, seja por dificuldades pontuais ou gerais, seja por experiências anteriores que registraram conteúdos emocionais negativos em suas mentes. Na impossibilidade do professor de Matemática lidar diretamente com a complexidade do mundo, esse professor precisa se mostrar cada vez mais hábil na criação de metáforas para a representação e solução de sua relação com esse mesmo mundo.

Esse processo de busca de uma visão bem estruturada da realidade é fundamentalmente um fenômeno de modelagem. Segundo Goldbarg (2000) [8] todos nós já lidamos com modelos, mesmo em ocasiões onde não possuíamos a mínima consciência disso. Quando explicamos algo a uma pessoa usando gráficos ou quando representamos sólidos através de equações matemáticas, nada mais estamos fazendo do que transmitir e interpretar a estranha realidade através de metáforas de substituição ou modelos.

Assim esse artigo propõe o estudo da Teoria dos Grafos no Ensino Médio, com o objetivo de promover o desenvolvimento proposto pelos PCN (Planos Curriculares Nacionais) e ainda causar uma mudança positiva nas relações dos estudantes com a Matemática, visto que a maioria sentem-se mais motivados ao estudo quando são capazes de vislumbrar que o conhecimento adquirido será útil, fará diferença em sua vida. Com a utilização das tecnologias, o estudante poderá assumir o papel de tomador de decisão o qual examinará inúmeras configurações viáveis de um determinado problema proposto e selecionará, dentro de certos critérios, as melhores.

\section{REFERENCIAL TEÓRICO}

A definição de Grafo não está totalmente padronizada. Abaixo seguem as definições e notação utilizadas segundo Scheinerman (2011) [7] e Rabuske (1992) [11].

Um Grafo não orientado é um par $G=G(V, E)$, onde $V$ é um conjunto finite e $E$ é um conjunto de subconjuntos de dois elementos de $V$. Os elementos de $V$ são chamados vértices do Grafo, e os elementos de $E$ são chamados de arestas do Grafo.

O grau de um vértice $v$, denotado por gr(v), é o número de arestas que incidem em $v$. Vértices ligados por arestas são ditos vértices adjacentes. Um Grafo é dito um multigrafo quando existem múltiplas arestas entre pares de vértices de $G$. Se o Grafo é orientado existe um conjunto $E$ de pares ordenados de vértices, denominados arcos ou arestas direcionadas. Se nenhuma aresta possui orientação, o Grafo é chamado de não orientado. E por fim, se um Grafo possui arcos e arestas, é denominado Grafo misto. Denota-se laço à aresta cujas extremidades estão em um mesmo vértice.

Diz-se que $G$ é um Grafo conexo quando existe um caminho ligando cada par de seus vértices.

Um ciclo em um Grafo é definido como um caminho fechado, isto é, passa-se em cada vértice de $G$ exatamente uma vez, exceto naturalmente no vértice inicial que é considerado também o terminal.

\subsection{ALGORITMO DE DIJKSTRA}

Um Grafo $G(V, E)$ é uma função de distância $L$ que associe cada aresta $(v, w)$ a um número real não negativo $L(v, w)$ e também um vértice fixo $v_{0}$ em $V$, chamado fonte. O problema consiste em se determinar os caminhos de $v_{0}$ para cada vértice $v$ de $G$, de tal forma que a somatória das 
distâncias das arestas envolvidas em cada caminho seja mínima. Isto é equivalente a determinar um caminho $v_{0}, v_{1}, \ldots \ldots, v_{k^{x}}$ tal que:

$\sum_{i=0}^{k-1} L\left(v_{i j}, v_{i+1}\right)$

seja mínimo.

O algoritmo de Dijkstra, tem a seguinte ideia:

Considere o diGrafo $G(V, E)$, uma fonte $v_{0}$ e uma função $L q u e$ associe cada aresta a um número real não negativo, isto é,

$$
L\left(v_{i}, v_{j}\right)=\left\{\begin{array}{l}
\infty, \text { se no existe a aresta }\left(v_{i}, v_{j}\right) . \\
0, \text { se }\left(v_{i}=v_{j}\right) . \\
\text { custo, se } v_{i} \neq v_{j} \text { e existe a aresta }\left(v_{i}, v_{j}\right) .
\end{array}\right.
$$

Constrói-se um conjunto $S$, que contém os vértices $v_{i}^{b} s$ cujo comprimento mínimo de $v_{0}$ a cada $v_{i}$, seja conhecido.

$>$ A cada passo se adiciona ao conjunto $S$ o vértice $w$ partencente a $V-S$ tal que o comprimento do caminho $v_{0}$ a $w$, seja menor do que o correspondente de qualquer outro vértice de $V-S$.

Pode-se garantir que o caminho mínimo de $v_{0}$ a qualquer vértice $v$ em $S$ contém somente vértices pertencentes a $S$.

Algoritmo de Dijkstra operando no Grafo.

Iniciamos pelo vértice $P$, a seguir fazemos:

Iteração (1) cor vermelha - Vértice Processado $A_{1}$

Iteração (2) cor azul - Vértice Processado $A_{4}$

Iteração (3) cor verde - Vértice Processado $A_{2}$

Iteração (4) cor lilás - Vértice Processado $A_{5}$

Iteração (5) cor amarela - Vértice Processado $A_{a}$

Iteração (6) cor laranja - Vértice Processado $A_{6}$

Terminamos com o vértice $Q$.

Queremos determinar o caminho do nó $\mathrm{P}$ ao vértice $\mathrm{Q}$. Então teríamos:

$Q-A_{6}-A_{2}-A_{5}-A_{2}-A_{4}-P$

$(2+1+2+3+2+4)=14$ 


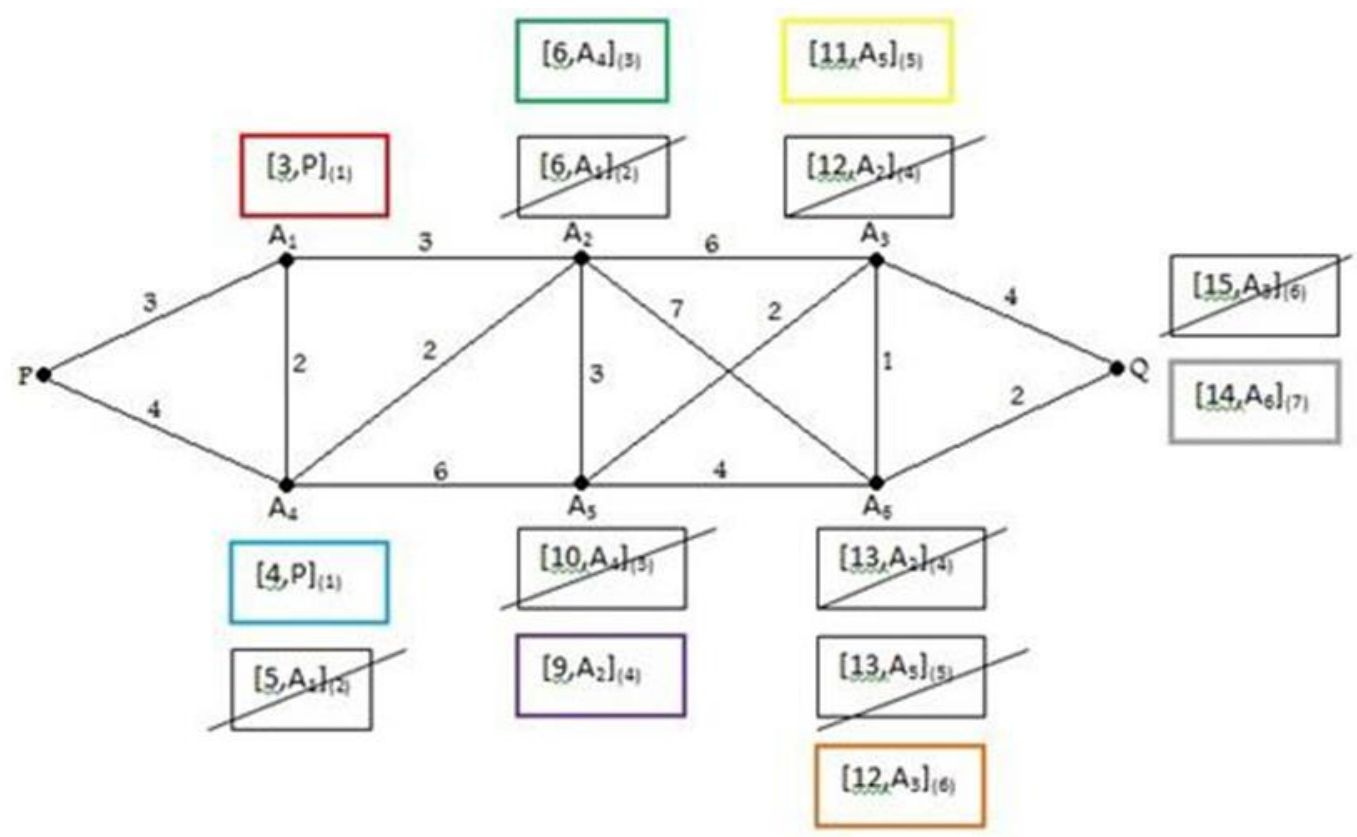

Figura 1: Algoritmo de Dijkstra operando no Grafo

\subsection{A ESCOLHA DO CONTEÚDO}

Nos dias de hoje, vemos a tecnologia avançando cada vez mais, e percebe-se a necessidade de tomadas de decisão para melhor desempenho de alguma atividade, pesquisar dados com capacidade seletiva, minimizar despesas, utilizar da melhor forma recursos escassos, entre outros. Todos esses são processos que requerem uma sequência de atitudes e pensamentos que se assemelham ao pensamento algorítmico. A partir do estudo do artigo de Junior (2007) [10], foram definidas algumas atividades a serem desenvolvidas em turmas de Ensino Médio. Neste artigo o objetivo principal não é o de descrever essas atividades passo a passo, mas sim refletir sobre qual o impacto podem causar na aprendizagem dos estudantes, além dos aspectos emocionais que envolvem esse tipo de trabalho.

Assim, como Junior (2007) [10], acredita-se que seja pertinente inserir nos conteúdos trabalhados no Ensino Médio a Teoria dos Grafos, de maneira a desenvolver conceitos básicos com os estudantes, para que eles possam entender a essência desses raciocínios. Alguns dos conceitos envolvidos nesse conteúdo são na área de combinatória, e é importante expandir a noção desse conceito na escola, pois acaba ficando restrito a problemas de contagem.

De acordo com Brasil (2006) [4]:

No Ensino Médio, o termo “combinatória" está usualmente restrito ao estudo dos problemas de contagem, mas esse é apenas um de seus aspectos. Outros tipos de problemas poderiam ser trabalhados na escola - são aqueles relativos a conjuntos finitos e com enunciados de simples entendimento relativo, mas não necessariamente fáceis de resolver. Um exemplo clássico é problema da pontes de Konisberg, tratado por Euler...

Problemas dessa natureza podem ser utilizados para desenvolver uma série de habilidades importantes: modelar o problema, via estrutura de Grafo - no exemplo, um diagrama em que cada ilha é representada por um ponto e cada ponte é um segmento conectando dois pontos; explorar o problema, identificando situações em que há ou não solução; convergir para a descoberta da condição geral de existência de uma tal solução...

Muitos outros exemplos de problemas combinatórios podem ser tratados de modo semelhante, tais como determinar a rota mais curta em uma rede de transportes ou determinar um eficiente trajeto para coleta de lixo de uma cidade. 
Além disso, nesse tipo de atividade é necessário que o estudante modele matematicamente o problema, reflita sobre as condições que o envolvem e crie estratégias para a resolução. Essas atividades desenvolvem no estudante habilidades relacionadas ao pensamento crítico, análise de soluções e autonomia, por exemplo.

\title{
2.3 PANORAMA GERAL DA ATIVIDADE E OS ASPECTOS EMOCIONAIS QUE O ENVOLVEM
}

Em primeiro lugar, é preciso esclarecer a crença na influência das emoções no processo de aprendizagem e que grande parte dos estudantes que apresentam dificuldades em relação à Matemática tem aspectos emocionais negativos ligados à essa disciplina durante o seu desenvolvimento escolar. De acordo com Buruchovitch (2001) [2]:

\begin{abstract}
A motivação tornou-se um problema de ponta em educação, pela simples constatação de que, em paridade de outras condições, sua ausência representa queda de investimento pessoal de qualidade nas tarefas de aprendizagem. E, ainda, à medida que as crianças sobem de série, cai o interesse e facilmente se instalam dúvidas quanto à capacidade de aprender certas matérias.
\end{abstract}

Conforme os anos do Ensino Fundamental vão passando, o desinteresse e a dificuldade em muitas matérias, principalmente na Matemática, vai aumentando. Quando o estudante chega ao Ensino Médio ele já possui uma autoimagem relacionada a sua capacidade de aprendizagem, que ainda é, infelizmente em sua maior parte, negativa com relação à essa disciplina.

Entendemos que tudo está interligado: a maneira como o professor pensa sobre educação, o processo de ensino e aprendizagem dos estudantes, o modo como o estudante é motivado ou não para determinada aula. De acordo com Cury (2003) [5]: "A educação moderna está em crise, porque não é humanizada, separa o pensador do conhecimento, o professor da matéria, o estudante da escola, enfim, separa o sujeito do objeto".

O trabalho que se propõe oferece um ambiente de troca e interação na sala de aula, tanto entre professor e estudante quanto entre os estudantes. Os jovens no primeiro momento da atividade precisam analisar o problema, os dados que possuem, os que podem ser procurados a partir desses, dessa forma realizar uma investigação prévia sobre o problema apresentado. Além de estarem sendo desafiados a propor soluções que sejam boas para a resolução de um problema real. De acordo com Goleman (2012) [9]:

\begin{abstract}
Os desafios - como ficar motivado para alcançar uma meta, ou ser convocado para exibir nossas melhores capacidades, ou para uma competição em equipe visando cumprir um prazo limite - concentram nossa atenção e extraem o melhor de nós no trabalho em questão. O bom estresse deixa-nos empenhados, entusiasmados e motivados, e mobiliza a quantidade certa de cortisol e adrenalina, os hormônios de estresse - junto com químicos cerebrais benéficos como a dopamina -,para se fazer o trabalho com eficácia.
\end{abstract}

Esse tipo de atividade, ao primeiro contato com o problema a ser resolvido, propõe um desafio permite ao estudante imaginar possibilidades, pensar em soluções que possam resolver e analisar a que melhor se encaixa. Durante essa fase surge, também, a importância do trabalho em equipe, o uso de conhecimentos e experiências prévias do estudante que podem ser relacionadas ao tema estudado, além da habilidade de interpretação e argumentação de porque pensa de uma forma ou outra.

O papel do professor é levar os estudantes a reflexão, a pensar se aquela solução que está sendo proposta realmente resolve o problema. Isso aproxima o professor da turma, pois ele deixa de ser detentor dos conhecimentos e passa a ser um mediador. Além disso, quando o pensamento do estudante é valorizado e todas as sugestões de resolução são levadas em consideração e 
discutidas, o estudante se entende como principal agente da sua aprendizagem e acaba desenvolvendo autoestima por perceber que é capaz de realizar aquilo que é proposto.

Em um segundo momento, a partir das discussões realizadas pela turma, o professor formaliza esses conhecimentos e apresenta os métodos que estão sendo desenvolvidos para auxiliar nessas resoluções. Após a análise inicial e a inferência de possíveis soluções os estudantes estão com o pensamento apto a receber essas informações e certamente fazem melhor uso delas do que se fossem dadas logo no início sem a etapa investigativa.

Como conclusão das atividades os estudantes escrevem sobre o que aprenderam e podem propor novas ideias, novos temas a serem trabalhados. Além disso, o professor pode pedir para que eles exponham suas dificuldades, o que gostaram na atividade, o que acreditam que poderia ser mudado. Dessa forma, ele pode ouvir os seus estudantes e estar sempre num processo de avaliação de sua prática.

Atividades com esse perfil, onde o estudante tem a liberdade para interagir e expor suas opiniões e bagagem de conhecimentos prévios auxiliam no desenvolvimento da autoestima e mudam a sua relação com a aprendizagem no futuro. De acordo com Damásio (1996) [6]:

\begin{abstract}
Não me parece sensato excluir as emoções e os sentimentos de qualquer concepção geral da mente, muito embora seja exatamente o que vários estudos científicos e respeitáveis fazem quando separamos emoções e os sentimentos dos tratamentos dos sistemas cognitivos. [...] Os sentimentos são tão cognitivos como qualquer outra imagem perceptual e tão dependentes do córtex cerebral como qualquer outra imagem.
\end{abstract}

Não pretende-se com isso esperar que haja uma súbita revolução no modo como os estudantes encaram a Matemática, mas sim, que isso seja o início de uma mudança e que através dos planejamentos feitos pelo professor e sua reflexão sobre a prática, possamos expandir esse tipo de aula para outros conceitos relacionados à Matemática.

Através da autonomia e da participação do estudante nas atividades em sala de aula, provavelmente haverá uma melhora na relação entre professor e estudantes, pois se estabelece uma relação de companheirismo, de auxílio. $\mathrm{O}$ estudante percebe aquilo que o professor espera dele, e, em grande parte das vezes, sem chegar a ter a consciência disso, ele responde com o comportamento que o professor espera. Por isso é tão importante a relação que se estabelece entre o professor e a turma, essa relação depende também de aspectos emocionais do docente ligados à sua atividade de ensinar. De acordo com Almeida (2012) [1]:

Os sentimentos que orientam a atividade cotidiana em geral e o pensar podem ser positivos (otimistas) ou negativos (pessimistas), e contribuem no processo cognitivo da pessoa numa determinada situação. No autoconceito de qualquer pessoa, esses dois sentimentos são muito influentes, impulsionando ou impedindo o desenvolvimento adequado da pessoa.

O professor estudando essas relações emocionais e entendendo que o desenvolvimento, empenho e participação dos estudantes em sala de aula estão ligados a diversos aspectos emocionais, está mais preparado para lidar com a diversidade e os eventuais problemas que podem surgir dentro da sala de aula. Isso o diferencia no modo como trata os estudantes, no modo como planeja suas aulas, no tipo de atividade que propõe.

Em relação a essa atividade que está sendo proposta, vale ressaltar que apesar de tudo não é esperado que se consiga atingir a todos os estudantes. O principal é que o professor tente, persista e acredite naquilo que propõe. Muitos estudantes

irão gostar muito desse tipo de atividade, outros são mais resistentes demoram mais para superar suas antigas barreiras com a aprendizagem. Mas esse é o papel do professor, proporcionar o ambiente favorável aquele estudante que já tem um bom desempenho cognitivo e trazer o estímulo e a valorização para aquele que já desistiu de acreditar na própria capacidade. É esse resultado que esperamos alcançar com essa proposta. 


\section{OBJETO DE APRENDIZAGEM DESENVOLVIDO}

A utilização de um Objeto Virtual de Aprendizagem na educação pode beneficiar o processo de ensino-aprendizagem e auxiliar, de forma simples, o entendimento de alguns conceitos sobre a Teoria dos Grafos. Desta forma, o objetivo desta atividade é fazer com que o estudante, por tentativa e erro, descubra qual é o menor caminho entre os pontos $\mathrm{P}$ e $\mathrm{Q}$.

Após apresentar o Objeto Virtual de Aprendizagem ${ }^{1}$ Figura 2 será feita a seguinte pergunta aos estudantes:

1) Qual é o menor custo que podemos obter saindo do ponto P e chegando ao ponto Q?

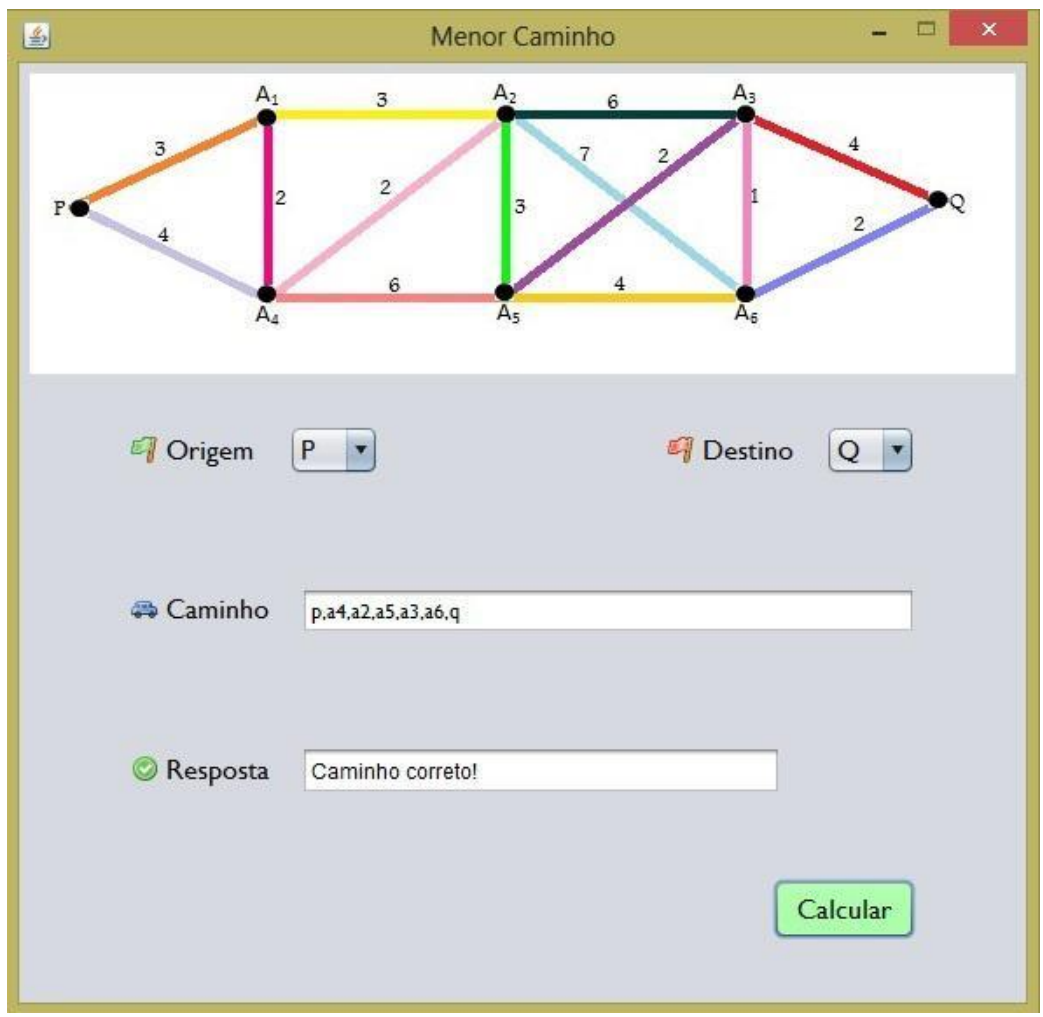

Figura 2: Objeto Virtual de Aprendizagem

Salienta-se que os segmentos, com o mesmo tamanho, apresentados acima podem possuir valores diferentes, uma vez que não representam a mesma distância e sim o custo ou tempo gasto para chegar até o destino.

Destaca-se também que o Objeto Virtual de Aprendizagem foi desenvolvido com o auxílio do estudante de Graduação em Engenharia de Computação Carlos Alberto S. do Nascimento da Silva Longo.

\section{RESULTADOS}

\subsection{TESTES REALIZADOS NA ESCOLA SILVA PAES}

Este trabalho foi desenvolvido com 24 estudantes, do $3^{\circ}$ ano do Ensino Médio na Escola Estadual Silva Paes, localizado no município Rio Grande, Estado do Rio Grande do Sul. Sendo aplicada em dois períodos, no dia 23 de março de 2016, na disciplina de Matemática.

São analisadas 12 respostas, visto que o laboratório de informática conta apenas com 12 computadores. 
1) Que raciocínio você utilizou para resolver a questão proposta?

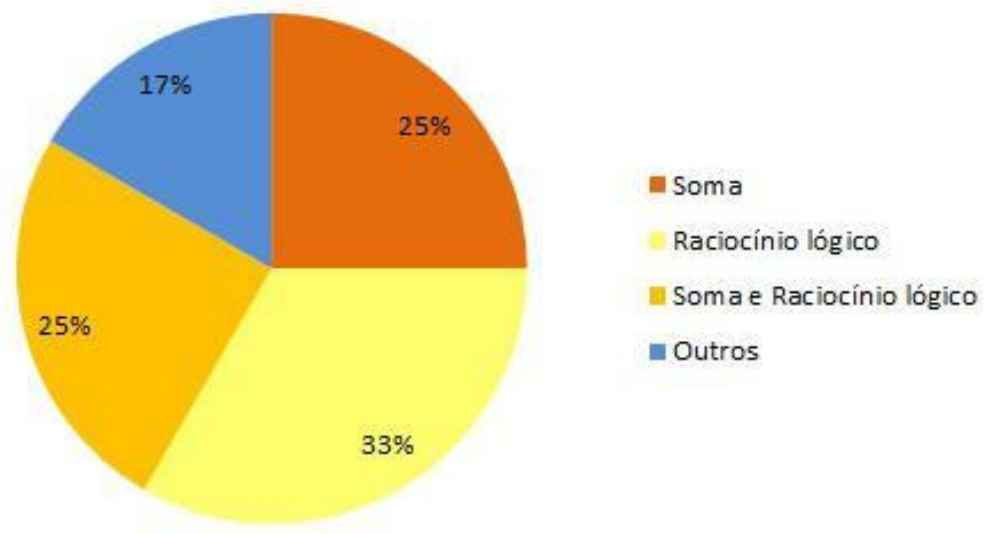

Figura 3: Estratégia de resolução dos estudantes da E.E.E.M Silva Paes

A maioria dos estudantes utilizou o raciocínio lógico para resolver a questão proposta, evidenciado no fragmento a seguir: "Nós procurados usar o menor valor possível de números, na tentativa de obter pequenos valores independente do caminho utilizado". Alguns encontraram a resposta correta através apenas da soma dos pesos das arestas, obtendo o menor custo sem realizar nenhum outro tipo de inferência lógica. As respostas são apresentadas na Tabela 1.

Tabela 1: Escola Silva Paes

\section{Respostas dos estudantes}

Soma.

Nós procurados usar o menor valor possível de números, na tentativa de obter pequenos valores independente do caminho utilizado.

A soma.

Utilizamos a soma e a lógica dos pontos.

Soma.

Raciocínio lógico, somamos os pontos até obter o menor resultado.

Eu tentei de diversas formas, até chegar em um resultado, o certo.

Utilizamos o raciocínio dos pontinhos para calcular.

Tentamos achar o menor caminho e não encontramos a melhor solução.

Raciocínio do menor caminho. E soma. E vértices.

Chegamos a um consenso comum para podermos concluir a atividade.

Pelos números menores.

\subsection{TESTES REALIZADOS NA ESCOLA LILIA NEVES}

Este trabalho foi desenvolvido com 10 estudantes, do $3^{\circ}$ ano do Ensino Médio na Escola Estadual Lilia Neves, localizado no município Rio Grande, Estado do Rio Grande do Sul. Sendo aplicada em dois períodos, no dia 29 de março de 2016, na disciplina de Matemática.

São analisadas 10 respostas, visto que o número de estudantes presentes no dia foi reduzido. $\mathrm{O}$ laboratório de informática contava apenas com 1 máquina e dois notebooks (três máquinas), pois os demais computadores não tinham acesso a internet para instalar o Objeto Virtual de Aprendizagem. Assim, optou-se por analisar as 10 respostas devido ao fato de que não havia computadores suficientes, ou seja, no mínimo 5 para que as atividades fossem realizadas em duplas. 


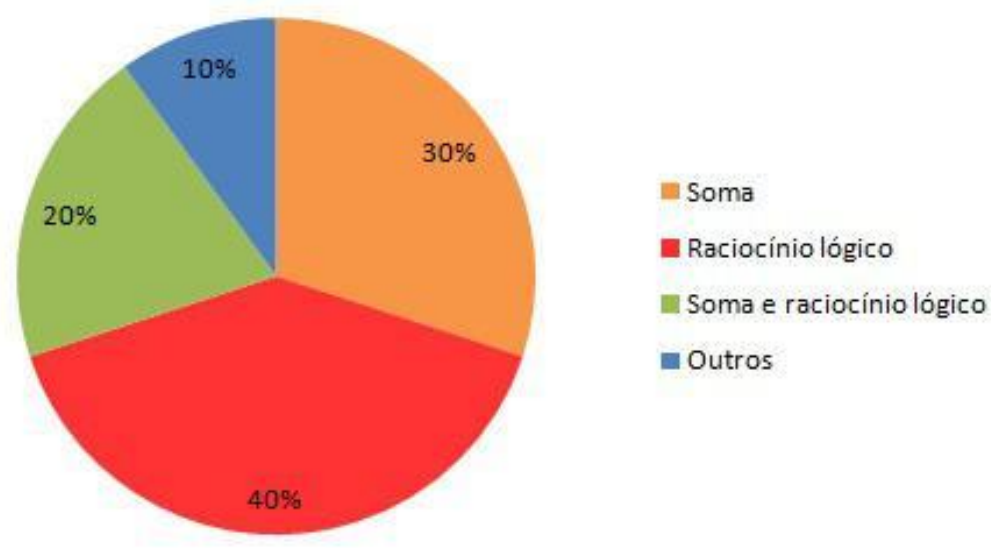

Figura 4: Estratégia de resolução dos estudantes da E.E.E.M Lilia Neves

Nesse caso pode-se dizer que $40 \%$ dos estudantes resolveram a Atividade utilizando o raciocínio lógico, como relatou o estudante: "Procurei seguir pelos menores números". Para 30\% dos estudantes a soma foi a estratégia de resolução utilizada. A resposta dada por $10 \%$ dos estudantes a qual atribui-se na figura como sendo da classe outros, ocorreu devido ao fato do estudantes responder a questão atravéz de um desenho dos pontos, ou seja, não pode-se afirmar que método o estudante utilizou para resolver o problema. As respostas são apresentadas na Tabela 2.

Tabela 2: Escola Lilia Neves

Respostas dos estudantes

A partir da soma dos valores dados pela atividade achei este caminho; P-A1-A2-A5-A3-A6-Q.

Fiz as somas.

Nas duas imagens podemos calcular qual o caminho mais próximo.

P-A1-A3-A4-A5-A6-Q, esse caminho, se somarmos os números, dá o melhor valor.

Procurei seguir pelos menores números.

Utilizando os menores caminhos.

Observando os menores números para ligar os traços.

Eu vi os menores números.

Eu utilizei o método de somar os menores números.

Eu usei o método da soma dos menores números.

Com isso, conclui-se que, de forma empírica, os estudantes utilizaram o algoritmo de Dijkstra para chegar a solução do problema proposto, que era sair do ponto $\mathrm{P}$ e chegar ao ponto $\mathrm{Q}$, com menor custo.

Vale ressaltar que para a classificação das respostas neste trabalho entende-se, raciocínio lógico como respostas onde houve o uso de inferência lógica. (Ex:"Raciocínio do menor caminho. E soma. E vértices"). Relacionado a classificação soma entende-se que as respostas envolviam apenas o uso de soma sem outras inferências. (Ex: "A soma").

\section{CONCLUSÕES}

A proposta deste trabalho foi embasado na inserção da Teoria dos Grafos no Ensino Médio, visto que esta proporciona a utilizacão de ferramentas acessíveis para a construção de modelos e na resolução de problemas, desde os mais simples aos mais elaborados. Acredita-se que as 
ferramentas computacionais possibilitam ao estudante o aprendizado e através da visualizacão, os estudantes conseguem articular a Matemática com os problemas do cotidiano.

É notável a desmotivação e a falta de interesse por parte dos estudantes em relação a Matemática. Diante disso propor um estudo diferenciado e com ele buscar mudanças positivas entre o estudante e as disciplinas estudadas pode contribuir de forma significativa para um melhor aprendizado. As emoções têm uma forte influência na aprendizagem, o professor além das obrigações pedagógicas assume também o papel de trabalhar com as emoções no ambiente escolar. Proporcionar ao estudante um ambiente favorável à aprendizagem na escola, oferecer escolhas que correspondam a sua necessidade proporcionando-os a liberdade de se expressar, fará com que se sintam mais a vontade para discutir as atividades propostas, e com isso torná-los mais interessados e atentos.

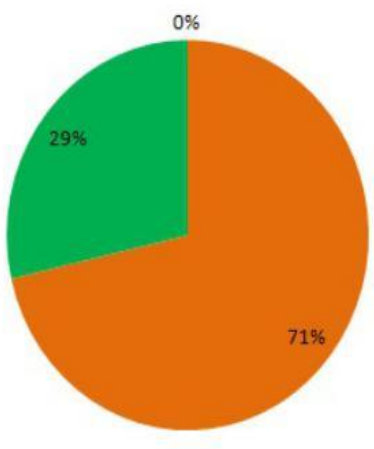

(a) Escola Silva Paes.

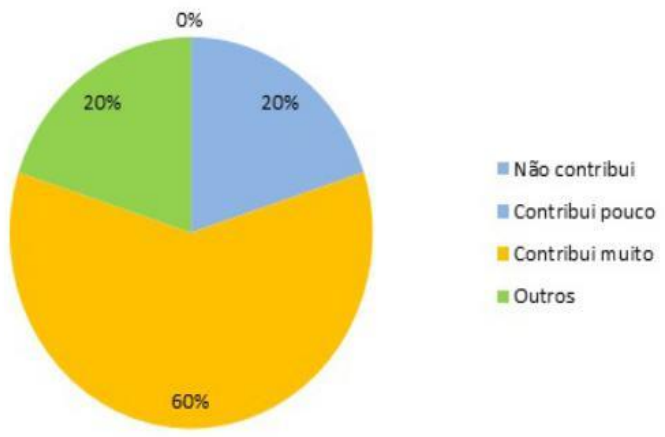

(b) Escola Lilia Neves.

Figura 5: Avaliação do Objeto Virtual de Aprendizagem

A Figura (5a) mostra que $71 \%$ dos estudantes aprovam o uso de Objeto Virtual de Aprendizagem para o ensino da Teoria dos Grafos, ou seja, os estudantes aprovam a utilização de novas metodologias de ensino, as quais os desafiem a pensar, discutir e chegar ao resultado. Neste tipo de atividade, nem sempre o estudante chega ao melhor resultado, mas participa, conhece algo novo, gerando conhecimento.

Já na Figura (5b) 60\% dos estudantes, avaliam que o Objeto Virtual de Aprendizagem contribui muito para o entendimento de Grafos, $20 \%$ relatam que esse tipo de atividade contribui, mas não especificaram quanto ela contribui se pouco ou muito. Observando as respostas é concluído que, em geral, os estudantes aprovam o uso de atividades diferenciadas em sala de aula.

Os resultados obtidos foram satisfatórios e os passos para a realização das atividades foram cumpridos, alcançando os objetivos gerais desse trabalho que é de inserir o conteúdo da Teoria dos Grafos no Ensino Médio. Proporcionar ao estudante novos métodos de ensino e novos conteúdos que podem facilmente ser inseridos no seu dia-a-dia contribui muito para uma aprendizagem mais interessante do ponto de vista do estudante.

\section{REFERÊNCIAS BIBLIOGRÁFICAS}

1. Almeida LR. Afetividade, Aprendizagem e Educação de Jovens e Adultos. Edições Loyola, São Paulo, Brasil. 2012, 160p.

2. Boruchovitch E, Bzuneck JA. A motivação do aluno: contribuições da psicologia contemporânea. 2001, 183p.

3. Brasil. Secretaria de Educação. Parâmetros curriculares nacionais: ensino médio. Brasília. MEC, 2002, 109p.

4. Brasil. Secretaria de Educação Básica. Orientações curriculares para o Ensino Médio. Volume 2. Ciências da Natureza, Matemática e suas Tecnologias. Brasília. MEC. 2006, 240p.

5. Cury A. Pais brilhantes, professores fascinantes. Sextante, Rio de Janeiro. 2003, 176p. 
6. Damásio AR. O erro de Descartes: emoção, razão e o cérebro humano. Editora Companhia das Letras, 1996, 259p.

7. Scheinerman ER. Matemática discreta: uma introdução. Edward R. Scheinerman, $2^{\circ}$ ed, São Paulo, Cengage Learning, 2011. $573 \mathrm{p}$.

8. Goldbarg MC, Luna HP. Otimização combinatória e programação linear. Rio de Janeiro: Campus. $2000,518 \mathrm{p}$

9. Goleman D. Inteligencia emocional. Editorial Kairós, 2012, 372p.

10. Junior, IM. Qual é o menor caminho? Conceitos, aplicações e experiências no ensino médio com teoria dos grafos \& algoritmos. In: XXIX Simpósio Brasileiro de Pesquisa Operacional. 2007, p.422-32.

11. Rabuske MA. Introdução à Teoria dos Grafos. Florianópolis. 1992, 184p. 